\title{
Informed consent: recommendations for its documentation
}

\author{
Miguel Ángel Celis, José Halabe, Oscar Arrieta, Rubén Burgos, Carlos Campillo, Manuel De la Llata, \\ Judith Domínguez, Sergio Islas, Luis Jasso-Gutiérrez, Alberto Lifshitz, Mucio Moreno, \\ Ricardo Plancarte-Sánchez, Alejandro Reyes-Fuentes, Guillermo Ruiz-Argüelles, Antonio Soda, \\ Emma Verástegui and Julio Sotelo \\ Comité de Ética y Transparencia en la Relación Médico-Industria (CETREMI), Academia Nacional de Medicina de México, Ciudad de México, Mexico
}

\begin{abstract}
Informed consent is an indispensable element to obtain adequate patient participation either in research protocols or in therapeutic design. The Committee of Ethics and Transparency in the Physician-Industry Relationship (CETREMI) of the National Academy of Medicine developed several recommendations for informed consent to be documented.
\end{abstract}

KEY WORDS: Human rights in Medicine. Medical ethics. Treatment acceptance. Participation authorization. Patient information. Defensive medicine.

The document known as informed consent is essential in modern medicine as a manifestation of respect for patient dignity and equality regarding the practice of professionals of medicine and research.

Considering the enormous relevance the informed consent has, the Committee of Ethics and Transparency in the Physician-Industry Relationship (CETREMI - Comité de Ética y Transparencia en la Relación Médico-Industria) of the National Academy of Medicine believes that this document should:

1. Recognize human equality in its principles and values. The informed consent is fundamentally a human act of equality (the patient) before another human being (the doctor), leaving behind the anachronistic attitude of medical paternalism, which attempts to place the doctor above the patient.

2. Accept that the informed consent is a medical act that goes beyond the declaration of risks-benefits. In daily practice, it constitutes a notification document of diagnostic procedures or invasive treatments that are necessary or beneficial, but which represent a potential risk or harm to the patient.
3. Revalue the informed consent act, which in daily routine has been devalued or distorted in many cases by using it primarily as a legal defense instrument against possible claims or lawsuits.

4. Reinforce the ethical scope the medical act should aspire to in terms of equality, dignity, autonomy and respect for the person.

5. Represent the best diagnostic or therapeutic procedure proposal, according to scientific evidence-based medicine, algorithms and clinical management guidelines.

6. Admit that the patient goes first and that it is an obligation not to make him/her suffer needlessly, not to violate his/her dignity, avoid additional risks and therapeutic obstinacy or additional financial benefits, arguing educational, research or innovation interests.

7. Promote transparency and accountability among physicians and health institutions. It is necessary for conflicts resulting from particular interests to be identified or prevented, by initiative of the pharmaceutical industry or suppliers of biomedical materials or equipment at the
Date of reception: 16-04-2018

Date of acceptance: 23-04-2018

DOI: 10.24875/GMM.M19000215
Gac Med Mex. 2018;154:615-616

Contents available at PubMed www.gacetamedicademexico.com 
moment of creating the informed consent. In procedures to be authorized, only that which is necessary should be used and that which is superfluous be avoided.

8. Document if decisions were the result of a medical collegiate or consensus meeting. If international models or guidelines are followed, the patient must be informed that the practical implementation is also valid or comparable for his/her own experience or that of the institution. Promote collegiate clinical discussion and document the decisions or management proposals that support the consent.

9. Promote training courses on how to obtain the informed consent among doctors and institutions, emphasizing on the dignified treatment and acceptance of the person's (patient) identity, which implies granting the patient a treatment as equals, neither as superiors nor as inferiors; and accepting differences in terms of religion, ethnicity, gender, social class, educational level, sexual orientation, age or disability without any prejudice.

10. Ensure the balance between quantity and quality of the information to be defined in the consent document: a) according to the urgency of the case (the greater the urgency, the lesser the accuracy claimable in the information), b) the need for treatment (if the intervention is less necessary, more rigor to sustain it, which must be extreme in case of cosmetic surgery), c) the danger or increased risk of complications, d) the novelty of the procedure, e) the severity of the disease (sensible balance between risk and benefit).

11. Should the patient refuse to accept necessary procedures due to economic shortcomings, the doctor should guide him/her to look for other medical-surgical options in public establishments.

In CETREMl's opinion, the following should be avoided:

a) Being too explicit and causing depression, anxiety or fear in patients when they know their diagnosis, if it was not as good as expected.

b) That the patient feels insecure and changes his/her doctor for another that lays out a more optimistic, not necessarily more realistic panorama, with less ethics and possibly less competent.

c) That, in public or private institutions, doctors with little experience obtain the informed consent. Routine, inertial or historical practices should be avoided.

d) Unduly informing the patient or family in order to induce them to accept a procedure that is not necessary or that involves excessive risk for the condition it is intended to address, in order to acquire experience for "integrating a case", with academic presentation or publication purposes, to be protected against possible complaints or lawsuits (defensive medicine), for commercial purposes or for economic benefit.

e) Maliciously informing the patient or family with the purpose to generate fear, seeking their dissent, in order to avoid the practice of a medical or surgical, diagnostic or therapeutic procedure, especially in public hospitals.

f) Giving alarming information aimed at being "covered" (defensive medicine) against possible complaints, lawsuits, risks, non-preventable adverse eventualities, risks of complication, lack of skill, incompetence or malpractice in the face of possible adverse results, when health professionals want to get rid of the patient with the purpose for him/her not to become a complainant or to look for another doctor.

g) In private medicine institutions, the informed consent document should not be omitted or to be inexplicit. The formal document should be a regular procedure in private medicine practice.

h) CETREMI emphasizes that the "informed consent" has not the purpose to protect the doctor against eventual lawsuits and claims, but to protect patients from eventual abuses or omissions by health personnel.Abstract 